Supporting Information

\title{
Cascade Reaction-Based Chemiresistive Array for Ethylene Sensing
}

Shinsuke Ishihara, ${ }^{, \dagger}$ Ashish Bahuguna, ${ }^{\dagger, \neq}$ Suneel Kumar, ${ }^{\dagger, \ddagger}$ Venkata Krishnan, ${ }^{\ddagger}$ Jan Labuta, ${ }^{\dagger}$ Takashi Nakanishi, ${ }^{\dagger}$ Takeshi Tanaka, ${ }^{*}$ Hiromichi Kataura, ${ }^{\#}$ Yoshihiro Kon, ${ }^{\Delta}$ and Dachao Hong ${ }^{*, \Delta}$

†International Center for Materials Nanoarchitectonics (WPI-MANA), National Institute for Materials Science (NIMS), 1-1 Namiki, Tsukuba 305-0044, Japan

¥School of Basic Sciences, Indian Institute of Technology Mandi, Mandi 175075, India

\#Nanomaterials Research Institute, National Institute of Advanced Industrial Science and Technology (AIST), Tsukuba 305-8565, Japan

${ }^{\Delta}$ Interdisciplinary Research Center for Catalytic Chemistry, AIST, Tsukuba 305-8565, Japan 


\section{Table of Contents}

\section{Experimental Section}

1.1. Materials

1.2. General methods

S3

1.3. Synthesis and characterization of catalysts

S3-S4

1.4. Preparation of SWCNT sensor

S5-S6

1.5. Procedure of creating diluted ethylene, acetaldehyde, and methane

S6

1.6. General procedure of creating VOC vapors

S7

1.7 Monitoring of catalytic activity

S7-S8

1.8. Evaluation of SWCNT sensors

S9

\section{Additional Data}

2.1. GC-MS

S10

2.2. Characterization of SWCNTs

S11

2.3. Sensing data

3. Determination of limit of detection (LoD)

$\mathrm{S} 18$

4. References

$\mathrm{S} 19$ 


\section{Experimental Section}

\subsection{Materials}

Chemicals and solvents were purchased from commercial sources and used as received unless stated otherwise. Palladium(II) chloride ( $\left.\mathrm{PdCl}_{2}\right)$, synthetic zeolite (A-4, 200 mesh), hydrochloric acid ( $\mathrm{HCl}$, guaranteed reagent), and nitric acid $\left(\mathrm{HNO}_{3}, 60-61 \%\right.$, guaranteed reagent) were purchased from Wako Pure Chemicals (Japan). Silica-alumina catalyst support (grade 135), ammonium vanadate $(\mathrm{V})\left(\mathrm{NH}_{4} \mathrm{VO}_{3}, 99 \%\right)$ and titanium dioxide $\mathrm{P} 25\left(\mathrm{TiO}_{2} \mathrm{P} 25\right)$ were obtained from Sigma-Aldrich (U.S.A.), Kanto Chemical (Japan) and EVONIK (Germany), respectively. Purified water $(18.2 \mathrm{M} \Omega \mathrm{cm}$ ) was obtained from a Milli-Q system (Direct-Q $3 \mathrm{UV}$, Millipore, U.S.A.). Ethylene (99.5\%) and methane (99.9\%) were purchased from GL Science (Japan). Acetaldehyde was obtained from Sigma-Aldrich (U.S.A.). Dimethylformamide, toluene, tetrahydrofuran, acetonitrile, ethanol, and acetone were obtained from Wako Pure Chemicals (Japan). $\mathrm{CDCl}_{3}, 1$-hexene, and 1-butyl-3-methylimidazolium tetrafluoroborate were obtained from Tokyo Chemical Industry (Japan).

\subsection{General methods}

Transmission electron microscopy (TEM) was performed using the JEM-2010 TEM (JEOL, Japan) operated at $200 \mathrm{kV}$ with energy-dispersive X-ray spectroscopy (EDS). SEM images were obtained using a Hitachi S-4800 scanning electron microscope operating at an accelerating voltage of $10 \mathrm{kV}$. XRD patterns were recorded on the MiniFlex600 diffractometer (Rigaku, Japan). Incident $\mathrm{X}$-ray radiation was produced by the $\mathrm{Cu} \mathrm{X}$-ray tube, operating at $40 \mathrm{kV}$ and 15 $\mathrm{mA}$ with $\mathrm{Cu}$ Ka radiation of $1.54178 \AA$. Raman spectra were obtained using a micro-Raman system (Horiba-Jobin-Yvon T64000) equipped with a Ar-Kr laser (514.5 nm). Scanning probe microscopy images (in tapping mode) were obtained using a commercial dynamic force microscopy (DFM) unit (SPA-400-SPI4000, Seiko Instrument Inc.) equipped with a calibrated 20- $\mu \mathrm{m}$ xy-scan and 10- $\mu \mathrm{m}$ z-scan range PZT-scanner. A rectangular-shaped silicon cantilever (SI-DF-20, Seiko Instrument Inc.) with a spring constant of $13 \mathrm{~N} \mathrm{~m}^{-1}$ and resonance frequency of $133 \mathrm{kHz}$ was used for imaging. All DFM operations were performed under air. Gas chromatography-mass spectrometry (GC-MS) was performed by the QP2010 GC-MS spectrometer (Shimadzu, Japan) [He carrier, GS-Carbon PLOT column (Agilent, U.S.A.)]. Concentration of ethylene, acetaldehyde, and ethanol was measured by detector tubes (GASTEC, No. 172 and $172 \mathrm{~L}$ for ethylene; No. 92M and 92L for acetaldehyde; No. 112L for ethanol).

\subsection{Synthesis and characterization of catalysts}

Synthesis of $\mathrm{V}_{2} \mathrm{O}_{5}-\mathrm{TiO}_{2}$. An aqueous solution (100 mL) containing $\mathrm{TiO}_{2} \mathrm{P} 25(1.0 \mathrm{~g})$ was stirred for $15 \mathrm{~min}$ at room temperature, and then to the reaction mixture, a $\mathrm{HNO}_{3}$ aqueous solution $(\mathrm{pH}$ $=4.0,10 \mathrm{~mL}$ ) with $\mathrm{NH}_{4} \mathrm{VO}_{3}(53.8 \mathrm{mg}, 0.46 \mathrm{mmol}$ ) was added. The mixture was stirred for $1 \mathrm{~h}$ at room temperature followed by evaporation under reduced pressure with subsequent drying in 
the oven at $120{ }^{\circ} \mathrm{C}$ for $12 \mathrm{~h}$ to give the as-prepared powder of $\mathrm{V}_{2} \mathrm{O}_{5}-\mathrm{TiO}_{2}$. The $\mathrm{V}_{2} \mathrm{O}_{5}-\mathrm{TiO}_{2}$ ( $4 \mathrm{wt} \%$ $\mathrm{V}_{2} \mathrm{O}_{5}$ ) was obtained by calcining the as-prepared powder at $400{ }^{\circ} \mathrm{C}$ for $4 \mathrm{~h}$ with the ramp rate of $5{ }^{\circ} \mathrm{C} \mathrm{min}^{-1}$.

Synthesis of $\mathbf{P d}-\mathrm{V}_{2} \mathrm{O}_{5}-\mathrm{TiO}_{2}$. $\mathrm{Pd}-\mathrm{V}_{2} \mathrm{O}_{5}-\mathrm{TiO}_{2}$ prepared by an impregnation method. In a typical procedure, the prepared $\mathrm{V}_{2} \mathrm{O}_{5}-\mathrm{TiO}_{2}(0.50 \mathrm{~g})$ was added into $0.50 \mathrm{M} \mathrm{HCl}$ solution containing $\mathrm{PdCl}_{2}$ (3.37 mg, $0.019 \mathrm{mmol}$ ) in a crucible. The mixture was sonicated for $10 \mathrm{~min}$ and calcined at $400{ }^{\circ} \mathrm{C}$ for $4 \mathrm{~h}$ with the ramp rate of $5^{\circ} \mathrm{C} \mathrm{min}^{-1}$. The obtained powder was denoted as $\mathrm{Pd}(\mathrm{STD})-\mathrm{V}_{2} \mathrm{O}_{5}-\mathrm{TiO}_{2}(0.4 \mathrm{wt} \% \mathrm{Pd}) . \mathrm{Pd}(\times 2)-\mathrm{V}_{2} \mathrm{O}_{5}-\mathrm{TiO}_{2}, \mathrm{Pd}(\times 1 / 2)-\mathrm{V}_{2} \mathrm{O}_{5}-\mathrm{TiO}_{2}$ and $\mathrm{Pd}(\times 1 / 4)-\mathrm{V}_{2} \mathrm{O}_{5}-$ $\mathrm{TiO}_{2}$ were prepared using different amount of $\mathrm{PdCl}_{2}(6.74,1.68$ and $0.84 \mathrm{mg}$, respectively) in the procedure. $\mathrm{Pd}(\mathrm{STD})-\mathrm{V}_{2} \mathrm{O}_{5}-\mathrm{TiO}_{2}$ was characterized by powder-XRD and TEM measurements (Fig. S1). $\mathrm{Pd}-\mathrm{V}_{2} \mathrm{O}_{5}-\mathrm{TiO}_{2}(200 \mathrm{mg}$ ) loaded in glass tube (with ends capped with glass wool) was supplied as a catalyst.

Synthesis of $\mathrm{Pd}-\mathrm{TiO}_{2}, \mathrm{Pd}$-zeolite and $\mathrm{Pd}-\mathrm{Si}_{-} \mathrm{Al}_{2} \mathrm{O}_{3}$. The $\mathrm{Pd}$ loaded catalysts was prepared by the impregnation method as described above. $\mathrm{Pd}-\mathrm{TiO}_{2}, \mathrm{Pd}$-zeolite and $\mathrm{Pd}-\mathrm{Si}-\mathrm{Al}_{2} \mathrm{O}_{3}$ were obtained from the mixture of $\mathrm{PdCl}_{2}(3.37 \mathrm{mg}, 0.019 \mathrm{mmol})$ and the support materials $(500 \mathrm{mg})$; $\mathrm{TiO}_{2} \mathrm{P} 25$, synthetic zeolite A-3 or silica-alumina catalyst, respectively.

a

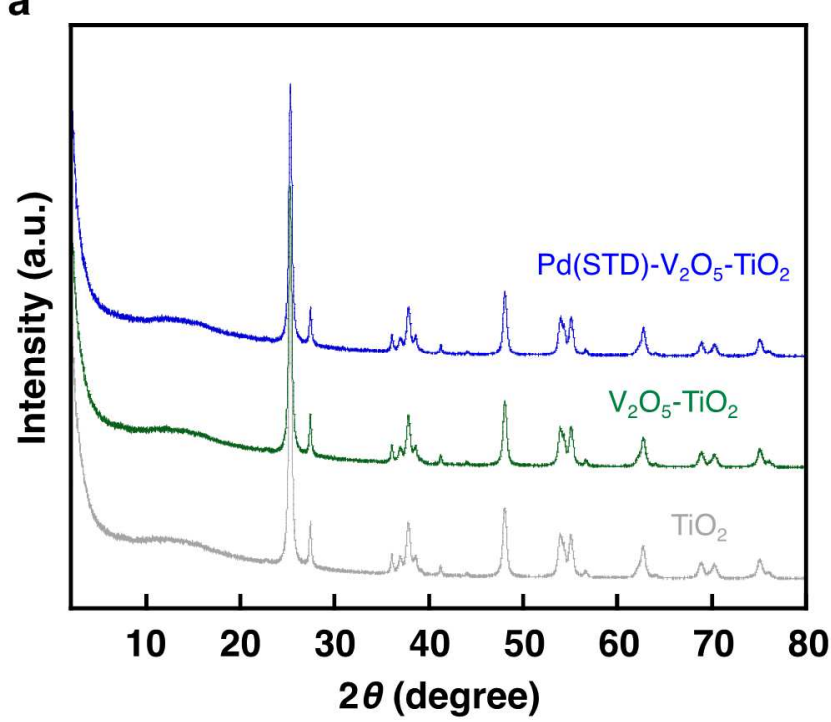

b

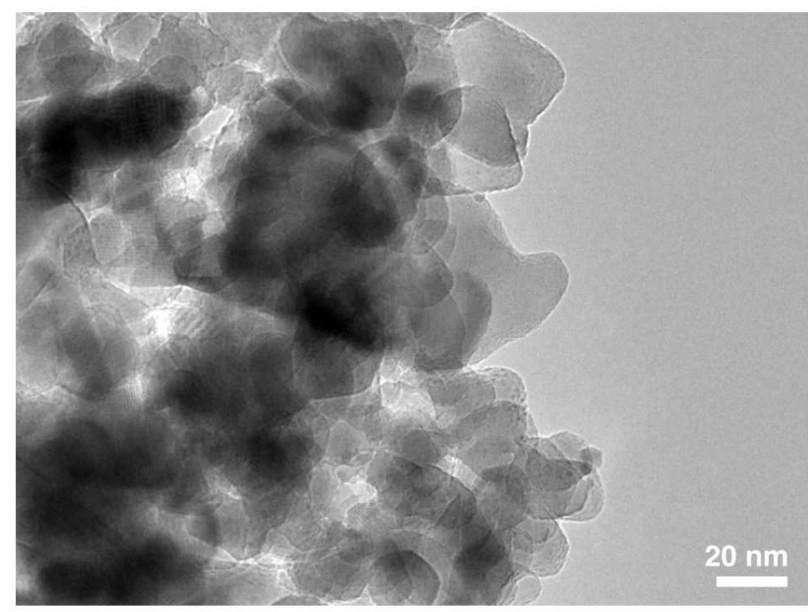

Figure S1. (a) Powder-XRD patterns of $\mathrm{Pd}(\mathrm{STD})-\mathrm{V}_{2} \mathrm{O}_{5}-\mathrm{TiO}_{2}, \mathrm{~V}_{2} \mathrm{O}_{5}-\mathrm{TiO}_{2}$ and $\mathrm{TiO}_{2}$. (b) TEM image of $\mathrm{Pd}(\mathrm{STD})-\mathrm{V}_{2} \mathrm{O}_{5}-\mathrm{TiO}_{2}$. 


\subsection{Preparation of SWCNT sensor}

Dispersion of SWCNTs. Sensor device based on SWCNT was prepared according to our previous report. ${ }^{\mathrm{S1}}$ SWCNTs prepared by high-pressure catalytic $\mathrm{CO}$ decomposition (HiPco, Nanolntegris, USA) were used as starting material, and isolation of semiconducting SWCNTs (> 95\%) were performed as we reported previously. ${ }^{\mathrm{S}} 0.02 \mathrm{mg}$ of semiconducting SWCNTs and $0.1 \mathrm{mg}$ of anthracene-based ligand (Scheme S1) were suspended in $0.2 \mathrm{~mL}$ of o-dichlorobenzene (o-DCB) and toluene mixture (1:2 in vol.). Copper acetate monohydrate dissolved in methanol (10.6 mM, $16.4 \mu \mathrm{L}$ ) was added to form metallo-supramolecular polymer (MSP). ${ }^{\mathrm{S} 3}$ MSP disperses SWCNTs due to wrapping of individual nanotubes. The suspension was treated in an ultrasonic bath for $30 \mathrm{~min}$ at room temperature. The suspension was centrifuged (6238 $\times$ g, $10000 \mathrm{rpm}, 15 \mathrm{~min}$, Rev Spin 102 from Revolutionary Science), and supernatant solution (top $50 \%$ ) was collected. The dispersion (ca. $0.5 \mu \mathrm{l}$ ) was drop-cast on interdigitated electrode. Interdigitated gold electrode with electrode gap of $200 \mu \mathrm{m}$ was purchased from BVT Technologies (No. CC1.W1). The solvent was removed in air. The dropcasting of the dispersion was repeated until the resistance of SWCNTs network reached desired values (typically $\sim 100 \mathrm{k} \Omega$, measured by a ohmmeter). Sensors were kept in glass vial with screw cap under air atmosphere, and the sensors were stable at least over 1 year. Note that the use of semiconducting SWCNTs and MSP are not mandatory, but effective for sensitivity improvement. ${ }^{\mathrm{S}}$

SWCNT dispersion was spin-coated (3000 rpm) on flat $\mathrm{SiO}_{2} / \mathrm{Si}$ substrate (SUMCO, n-doped, 4"N, $0.00-0.02 \Omega \mathrm{cm}$, (100) surface, thickness of $\mathrm{SiO}_{2}=300 \mathrm{~nm}$ ) for scanning probe microscopy imaging.

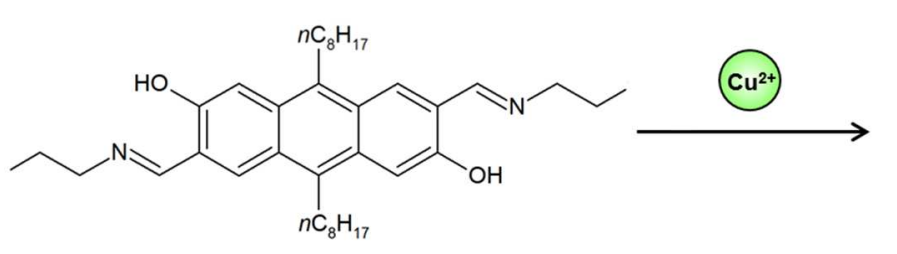

Ligand

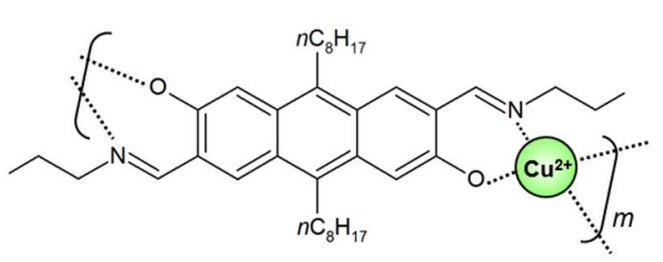

MSP

Scheme S1. Chemical structure of MSP used for dispersion of SWCNTs.

Decoration with $\mathrm{HA} \cdot \mathrm{HCl}$. Hydroxylamine hydrochloride $(\mathrm{HA} \cdot \mathrm{HCl})$ was added into methanol until saturation (ca. $100 \mathrm{mg} / \mathrm{mL}$ ). Then, the solution of $\mathrm{HA} \cdot \mathrm{HCl}$ was drop-casted on PTFE membrane filter $(0.2 \mu \mathrm{m}$, Millipore, Ominipore membrane filter, JGWP). Then, methanol was dried under air. Loading amount of $\mathrm{HA} \cdot \mathrm{HCl}$ was approximately $0.5 \mathrm{mg}$. PTFE membrane filter were cut to adjust size, and SWCNTs sensors were covered with them. Note that thin spacer $(0.4 \mathrm{~mm})$ was inserted between SWCNTs sensor and PTFE filter for promoting diffusion of analyte gases. PTFE filter was fixed by tape (Scheme S2). 


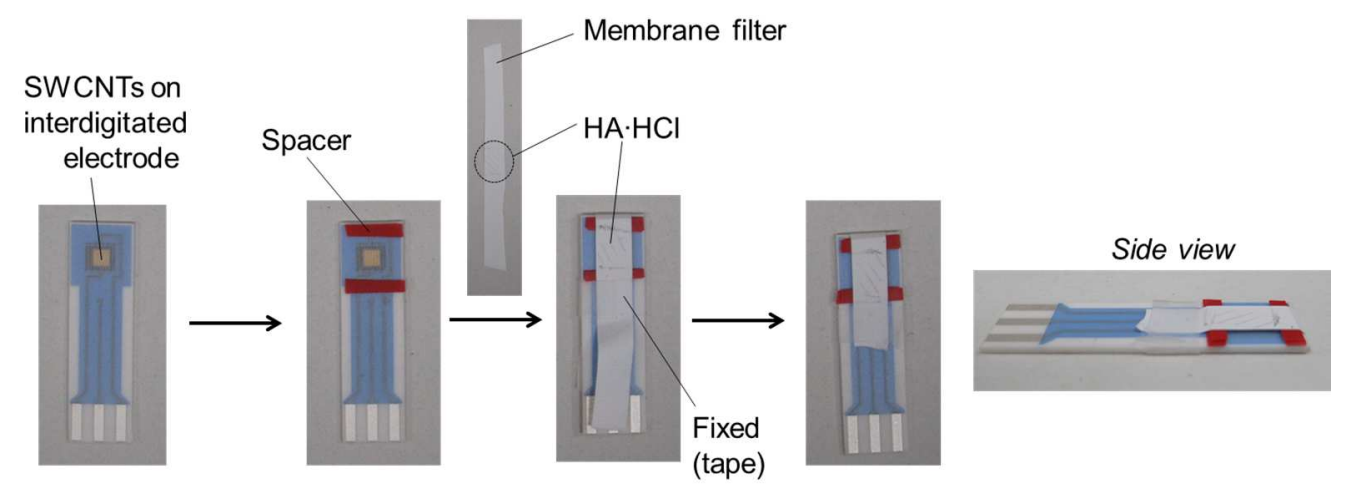

Scheme S2. Procedure of functionalizing SWCNTs sensors with hydroxylamine derivatives.

\subsection{Procedure of creating diluted ethylene, acetaldehyde, and methane}

Humidity-adjusted air was prepared as shown in Scheme S3. Dry air was supplied from gas cylinder or dry air generator (IAC, P4-EFA). Relative humidity (RH) was controlled by mixing dry and wet air, and monitored by digital RH sensor (VAISALA, HMI41). Pure ethylene (0.5 mL or $5.0 \mathrm{~mL}$ taken by syringe) was mixed into $5 \mathrm{~L}$ Tedlar bag containing humidity-adjusted air to prepare $100 \mathrm{ppm}$ or $1000 \mathrm{ppm}$ ethylene in air. Concentration of ethylene was confirmed by detector tube (GASTEC, No. 172 or $172 \mathrm{~L}$ ). Then, $50 \mathrm{~mL}$ of $100 \mathrm{ppm}$ ethylene or $1000 \mathrm{ppm}$ ethylene in air were mixed into $5 \mathrm{~L}$ Tedlar bag containing humidity-adjusted air to prepare $1 \mathrm{ppm}$ or $10 \mathrm{ppm}$ ethylene, respectively. $50 \mathrm{~mL}$ of $10 \mathrm{ppm}$ ethylene in air were mixed into $5 \mathrm{~L}$ Tedlar bag containing humidity-adjusted air to prepare $0.1 \mathrm{ppm}$ ethylene.

Saturated vapor of acetaldehyde $(5.0 \mathrm{~mL}$ taken by syringe) was mixed into $5 \mathrm{~L}$ Tedlar bag containing humidity-adjusted air to prepare $1000 \mathrm{ppm}$ acetaldehyde in air. Concentration of acetaldehyde was confirmed by detector tube (GASTEC, No. 92). Then, $50 \mathrm{~mL}$ of $1000 \mathrm{ppm}$ acetaldehyde in air was mixed into $5 \mathrm{~L}$ Tedlar bag containing humidity-adjusted air to prepare $10 \mathrm{ppm}$ acetaldehyde.

Pure methane $(5.0 \mathrm{~mL}$ taken by syringe) was mixed into $5 \mathrm{~L}$ of Tedlar bag containing humidity-adjusted air to prepare 1000 ppm methane in air.

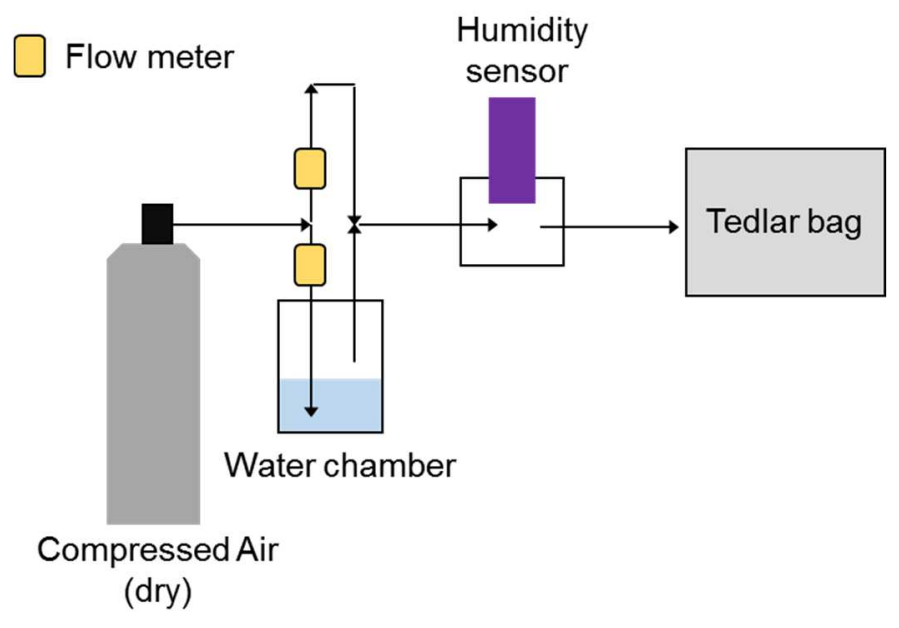

Scheme S3. Experimental set-up for preparing humidity-adjusted air. 


\subsection{General procedure of creating VOC vapors}

For measuring device response to volatile organic compounds, a handmade gas generator system was used to produce analyte gas with known concentration (Scheme S4). ${ }^{\text {S1 Under }}$ constant flow rate and temperature, mass of analyte liquid in test tube (ca. $1 \mathrm{~mL}$ of liquid in 15 $\mathrm{mL}$ test tube) was measured every $1 \mathrm{hr}$ for three times, and averaged evaporation rate of analyte was calibrated based on the decrease of mass. Typically, flow rate of air was $300 \mathrm{~mL} / \mathrm{min}$, and temperature of thermostatic bath was $40^{\circ} \mathrm{C}$. This procedure was applied for 1 -hexene, toluene, chloroform, tetrahydrofuran, acetonitrile, and ethanol. Concentration of ethanol (500 ppm) obtained by weight-loss was consistent with the value determined by the detector tube. Thus, VOC vapors were collected into Tedlar bag.

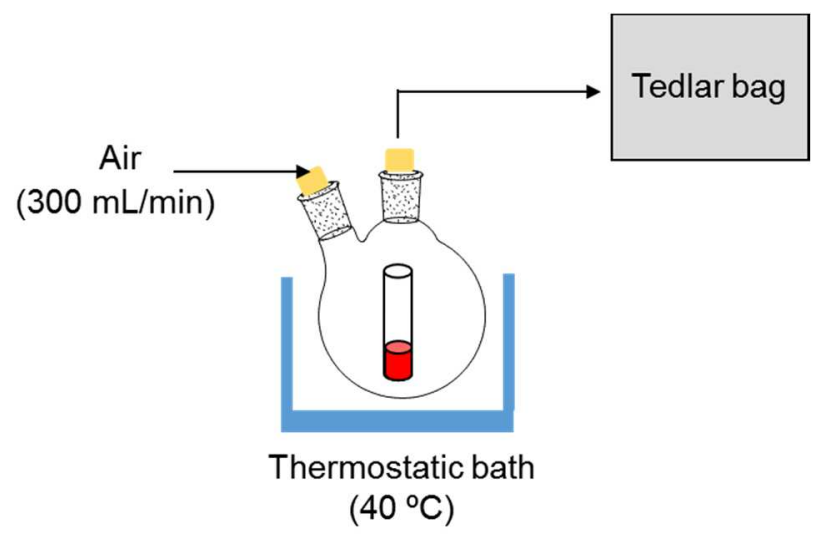

Scheme S4. Experimental set-up for creating VOC vapors.

\subsection{Monitoring of catalytic activity}

Homogeneous catalysis. Catalytic activity of homogeneous catalysts was tested as shown in Scheme S5. Ethylene in air (in $5 \mathrm{~L}$ Tedlar bag) was delivered by electrically-powered pump (GASTEC, GSP-400FT), and bubbled into the catalysis solution. When catalysis solution was warmed, the reactor was equipped with a condenser to capture water (Dean-Stark apparatus cooled by circulated water). The outlet gas was monitored by detector tube for acetaldehyde (GASTEC $92 \mathrm{~L}$ or 92M) and ethylene (GASTEC 172 or 172L). When necessary, outlet gas was diluted with ambient air prior to injection to detector tube (for adjusting to standard flow rate), and actual concentration of analyte was calculated based on the degree of dilution. 


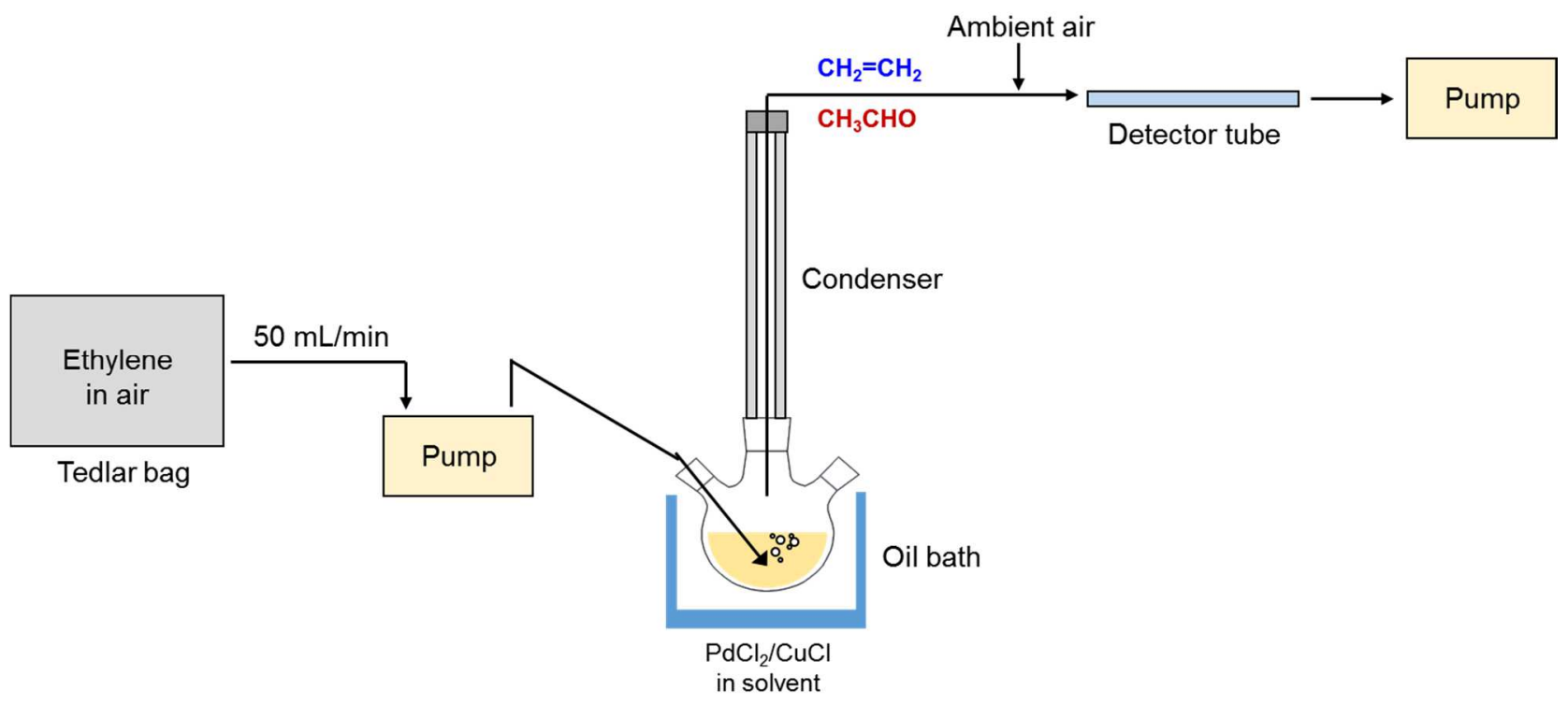

Scheme S5. Experimental set-up for estimating the activity of homogeneous catalysts.

Heterogeneous catalysis. Catalytic activity of heterogeneous catalysts was tested as shown in Scheme S6. Ethylene in air (in $5 \mathrm{~L}$ Tedlar bag) was delivered by electrically-powered pump (GASTEC, GSP-400FT). Flow rate was reconfirmed by digital flow meter (Ellutia, 7000 Flowmeter). Ethylene was passed through the heterogeneous catalysts loaded in glass tube (warmed in electric oven, IW-300, ETTAS). The outlet gas was monitored by detector tube for acetaldehyde (GASTEC 92M). Since the standard flow rate of the detector tube is $100 \mathrm{~mL} / \mathrm{min}$, ambient air $(75 \mathrm{~mL} / \mathrm{min})$ was mixed into the analyte air. Thus, actual concentration of acetaldehyde should be fourfold of the value shown in detector tube.

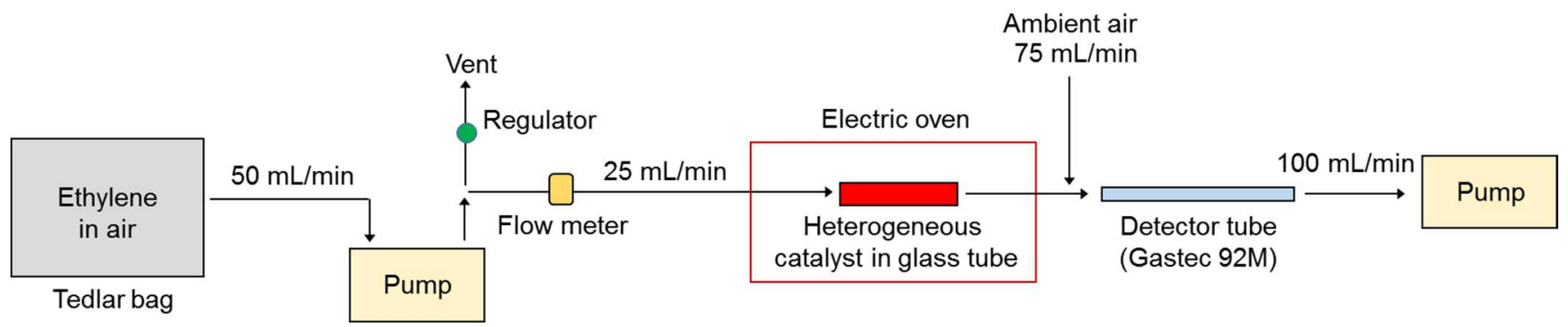

Scheme S6. Experimental set-up for estimating the activity of heterogeneous catalysts. 


\subsection{Evaluation of SWCNT sensors}

With clean air. Responses of SWCNT sensors were acquired as shown in Scheme S7 (see also Fig. 2a in the main manuscript). Clean air and catalyst-passed analyte gas were switched manually. Interdigitated electrode (see Scheme S2) was connected to a potentiostat (PalmSens EmStat). A constant potential of $0.10 \mathrm{~V}$ was applied across the electrodes, and the current was recorded using PSTrace software (v. 4.8).

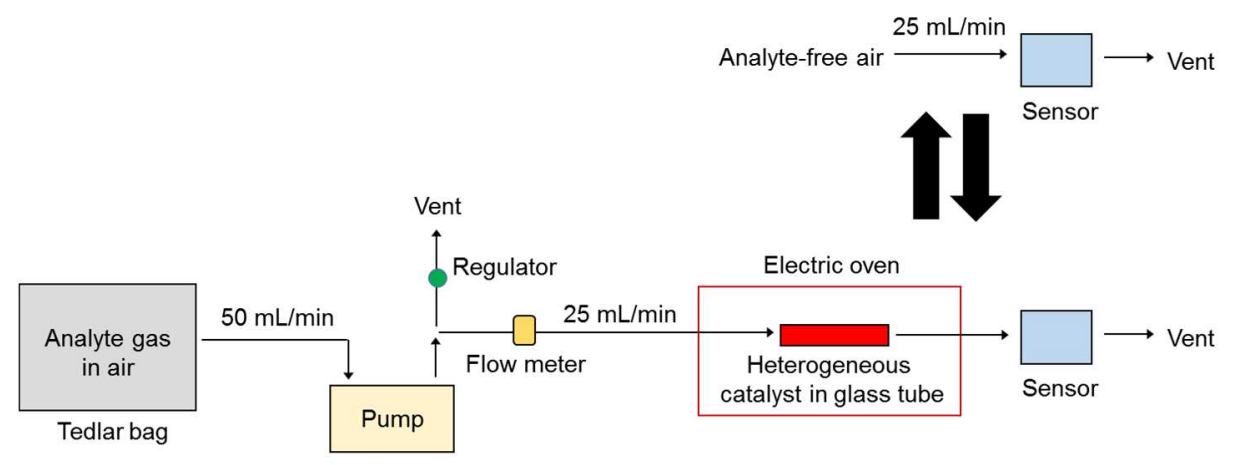

Scheme S7. Experimental set-up for estimating responses of SWCNT sensor. Analyte-free air (up) and catalyst-passed analyte air (bottom) were switched so as to estimate $I_{0}$ and $I$, enabling the calculation of normalized electric response.

Without clean air. Responses of SWCNT sensors were acquired as shown in Scheme S8 (see also Fig. 4a in the main manuscript). Analyte gas (detoured catalyst) and catalyst-passed analyte gas were switched manually. Interdigitated electrode (see Scheme S2) was connected to a potentiostat (PalmSens EmStat). A constant potential of $0.10 \mathrm{~V}$ was applied across the electrodes, and the current was recorded using PSTrace software (v. 4.8).

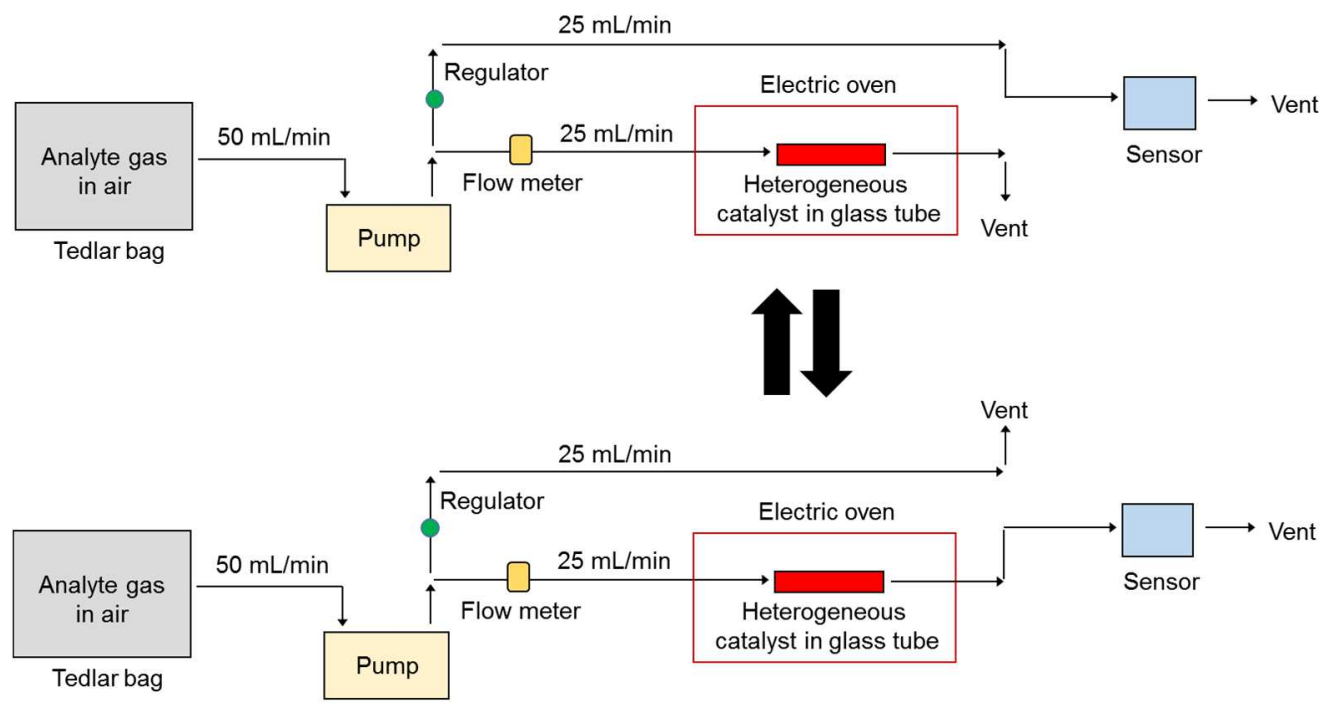

Scheme S8. Experimental set-up for estimating responses of SWCNT sensor. Analyte air (up) and catalyst-passed analyte air (bottom) were switched so as to estimate $I_{0}$ and $I$, enabling the calculation of normalized electric response without analyte-free air. 


\section{Additional Data}

\subsection{GC-MS}

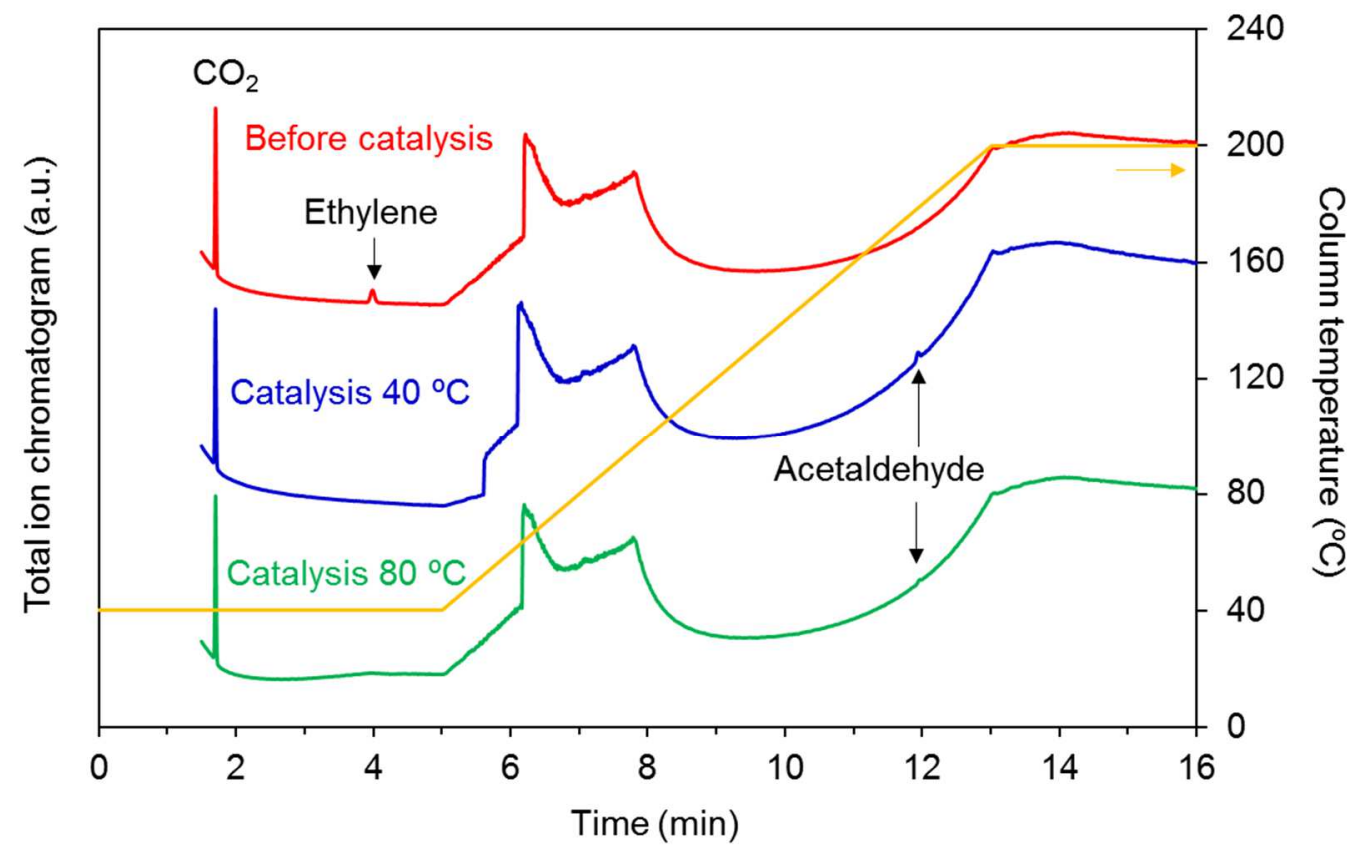

Figure S2. GC-MS profile of $100 \mathrm{ppm}$ ethylene in air (50\% RH) before and after passing through $\mathrm{Pd}(\mathrm{STD})-\mathrm{V}_{2} \mathrm{O}_{5}-\mathrm{TiO}_{2}$ catalyst (Entries 5 and 8 in Table 1). Analyte gas $(100 \mu \mathrm{L})$ was injected into the instrument without pretreatment. Ethylene signal (ca. $4 \mathrm{~min}, 28 \mathrm{~m} / \mathrm{z}$ ) disappeared after catalysis at $40^{\circ} \mathrm{C}$ and $80^{\circ} \mathrm{C}$. Catalysis at $40^{\circ} \mathrm{C}$ exhibited larger signals of acetaldehyde (ca. 12 $\mathrm{min}, 44 \mathrm{~m} / \mathrm{z}$ ) than that of $80^{\circ} \mathrm{C}$, which is consistent with the conversion yields determined by detector tube (Table 1). $\mathrm{CO}_{2}$ signals (ca. $1.7 \mathrm{~min}, 44 \mathrm{~m} / \mathrm{z}$ ) are mainly derived from air, and there are no significant differences before and after catalysis. Acetic acid, which should appear around 14 min (this time was confirmed by separate experiment; data not shown), was not detected after catalysis presumably due to strong adsorption of acetic acid on $\mathrm{TiO}_{2}$. 


\subsection{Characterization of SWCNTs}

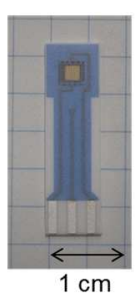

d
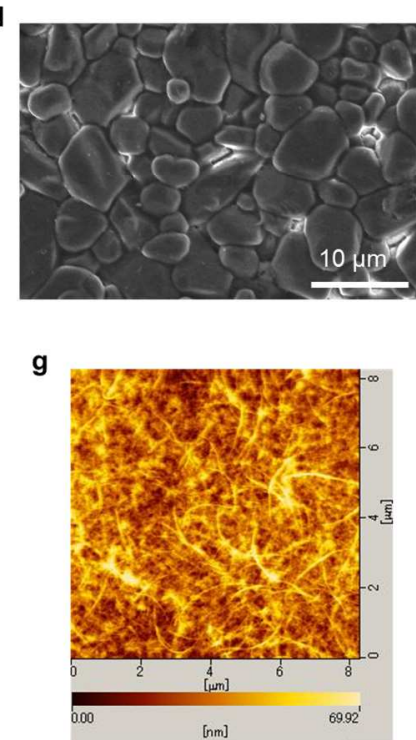

b
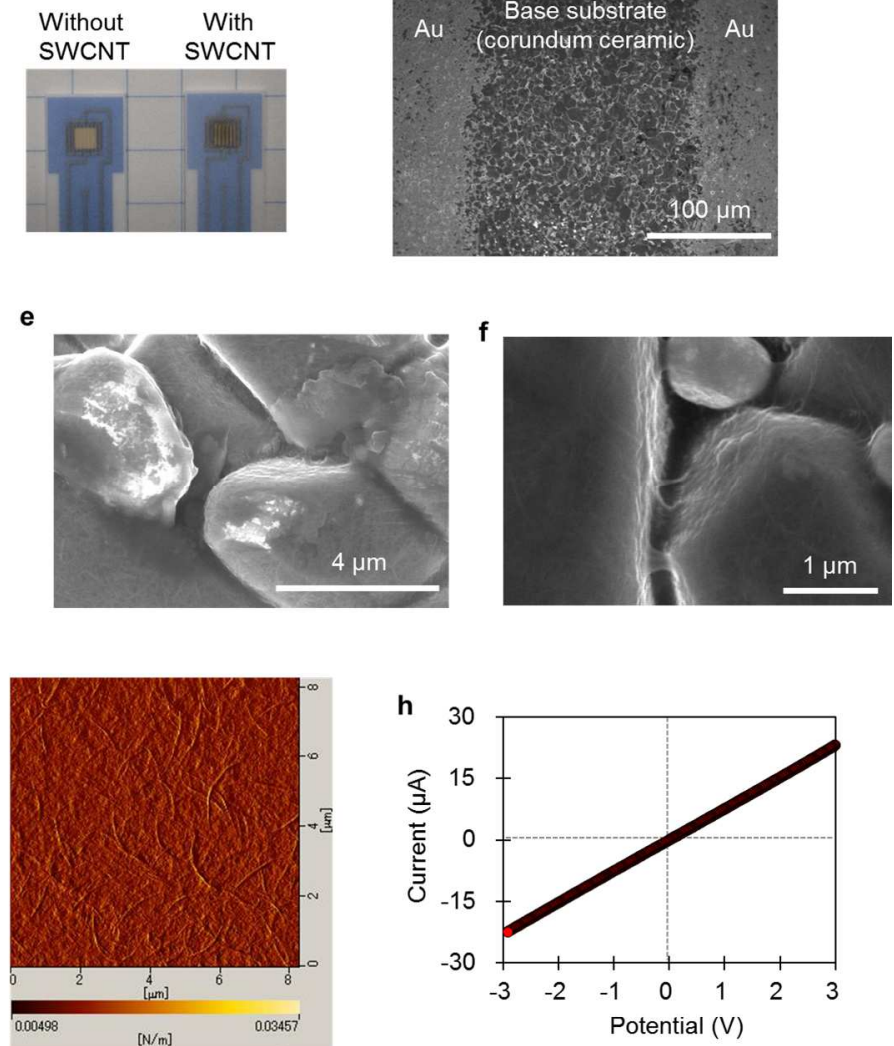

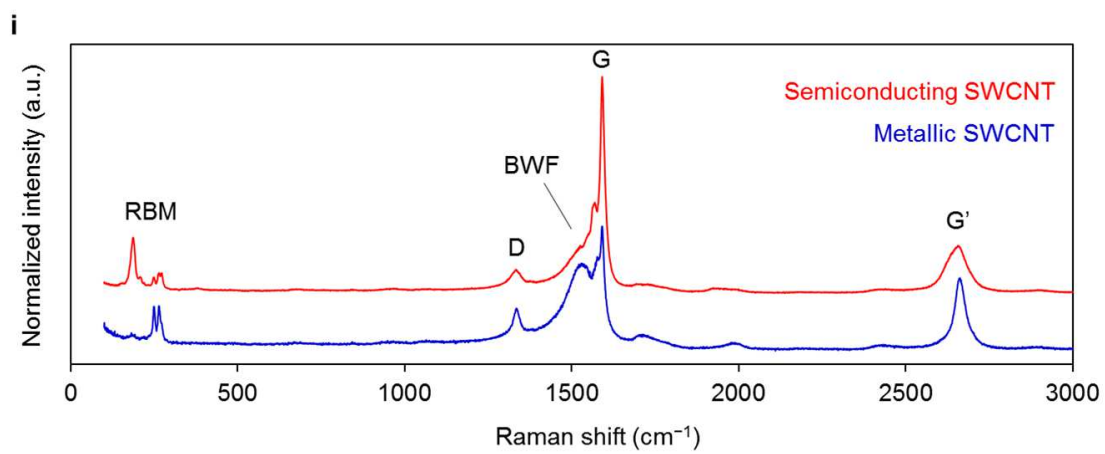

Figure S3. Characterization of SWCNT. (a) Photograph of interdigitated electrode comprised of ceramic substrate and gold lines with gap distance of $200 \mu \mathrm{m}$. (b) Photograph of interdigitated electrode with and without SWCNT. (c-f) SEM image of interdigitated electrode embedded with SWCNT. (g) Scanning probe microscopy images of SWCNT spin-coated (3000 rpm) on flat $\mathrm{SiO}_{2} / \mathrm{Si}$ substrate. (h) $\mathrm{I}-\mathrm{V}$ curve $(0 \mathrm{~V} \rightarrow 3 \mathrm{~V} \rightarrow-3 \mathrm{~V} \rightarrow 0 \mathrm{~V})$ for interdigitated electrode embedded with SWCNT (scan rate $=0.1 \mathrm{~V} \mathrm{~s}^{-1}$ ) measured under ambient air. (i) Raman spectra of SWCNTs (metallic and semiconducting) separated by column chromatography. ${ }^{22}$ RBM and BWF denote radial breathing mode and Breit-Wigner-Fano band, respectively. 


\subsection{Sensing data}

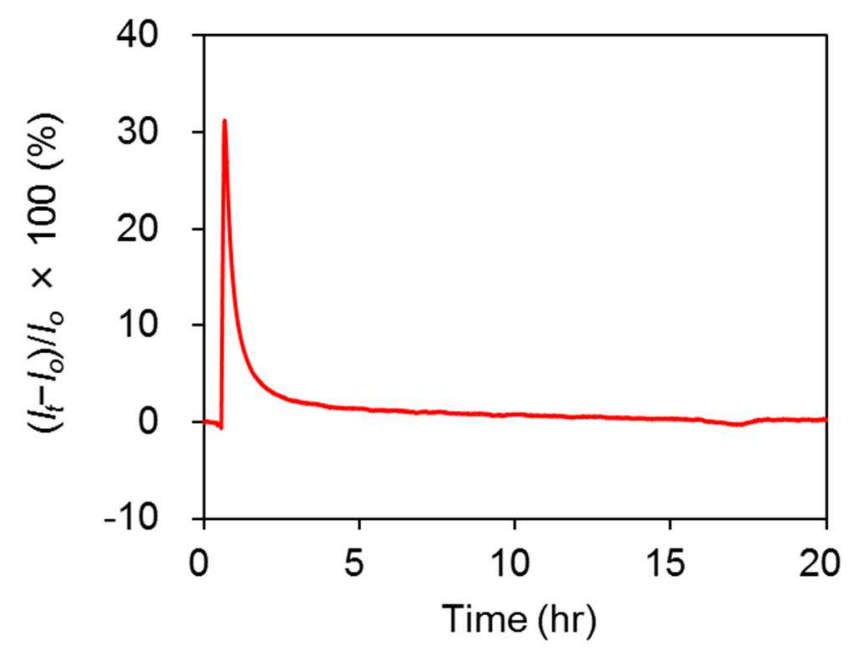

Figure S4. Full recovery of the sensor. After response to air with analyte (ethylene $10 \mathrm{ppm}$ in $50 \%$ $\mathrm{RH}$ air, $\left.25 \mathrm{~mL} \mathrm{~min}{ }^{-1}\right)$, the sensor was exposed to clean air $\left(50 \% \mathrm{RH}, 25 \mathrm{~mL} \mathrm{~min}{ }^{-1}\right)$ for hours. Experimental set-up is based on Figure 2a.

a

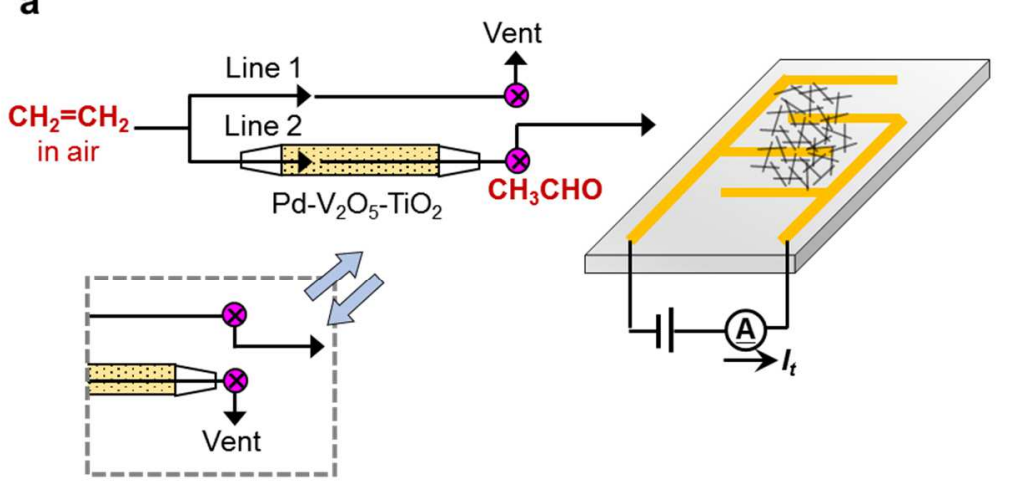

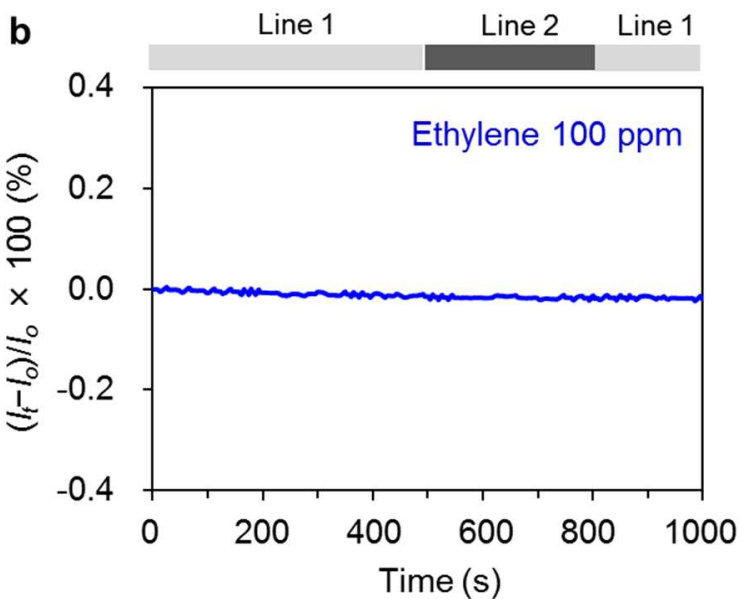

Figure S5. Response to ethylene in the absence of $\mathrm{HA} \cdot \mathrm{HCl}$. (a) Illustration of sensing system equipped with a switch to exclude $\mathrm{Pd}-\mathrm{V}_{2} \mathrm{O}_{5}-\mathrm{TiO}_{2}$. (b) Electric response of sensors for ethylene (100 $\mathrm{ppm})$ in air $\left(50 \% \mathrm{RH}, 25 \mathrm{~mL} \mathrm{~min}{ }^{-1}\right)$. Sensor was exposed to analyte gas passed through $\mathrm{Pd}-\mathrm{V}_{2} \mathrm{O}_{5}-$ $\mathrm{TiO}_{2}$ (thus containing $\mathrm{CH}_{3} \mathrm{CHO}$ ) (Line 2; 500-800 sec), but no response. 

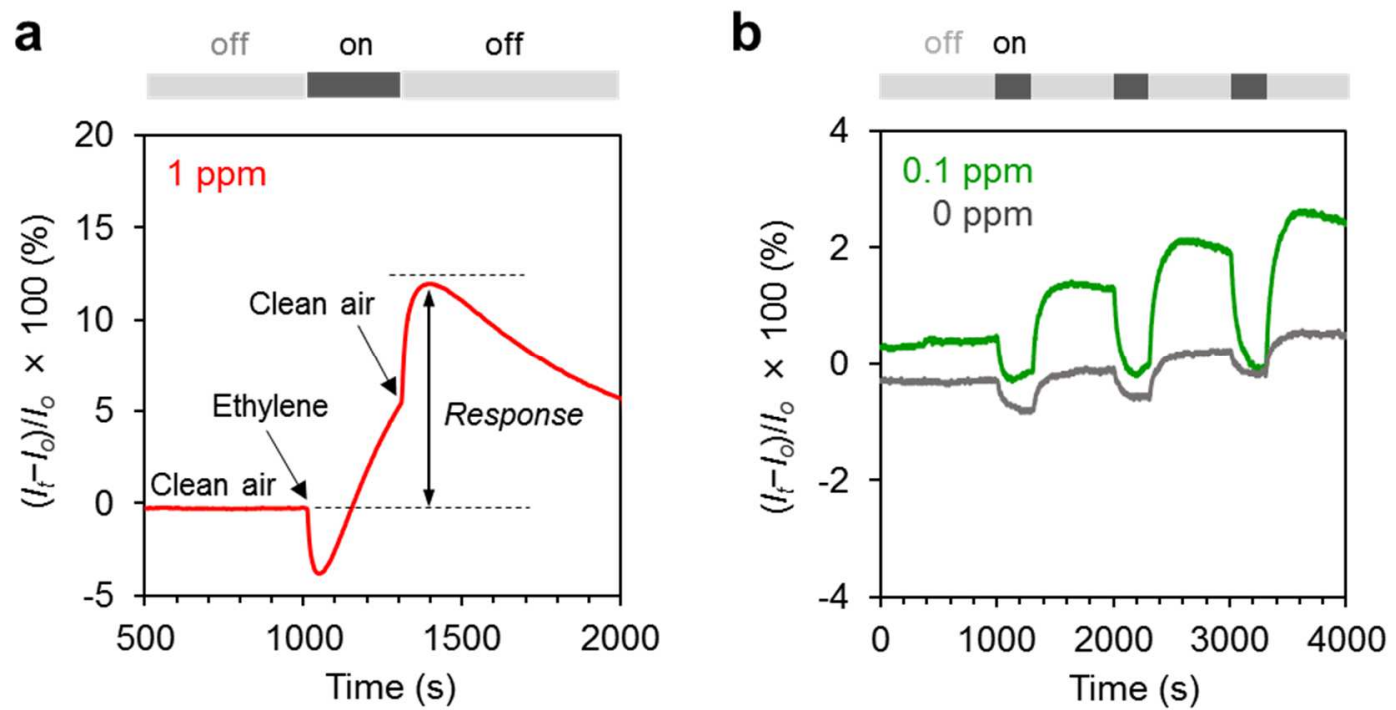

Figure S6. (a) Enlarged image of Figure 2b (for $1 \mathrm{ppm}$ ethylene). Decrease and increase of electric current upon switching to ethylene and clean air would be due to subtle change in $\mathrm{RH}$. (b) Electric response of sensors for ethylene (0 and $0.1 \mathrm{ppm})$ in air $\left(50 \% \mathrm{RH}, 25 \mathrm{~mL} \mathrm{~min}^{-1}\right)$. Analyte gases were passed through $\mathrm{Pd}-\mathrm{V}_{2} \mathrm{O}_{5}-\mathrm{TiO}_{2}(200 \mathrm{mg})$ kept at $40{ }^{\circ} \mathrm{C}$. Exposure to clean air ("off", $700 \mathrm{sec}$ ) and catalyst-passed analyte air ("on", $300 \mathrm{sec}$ ) were repeated for three times.

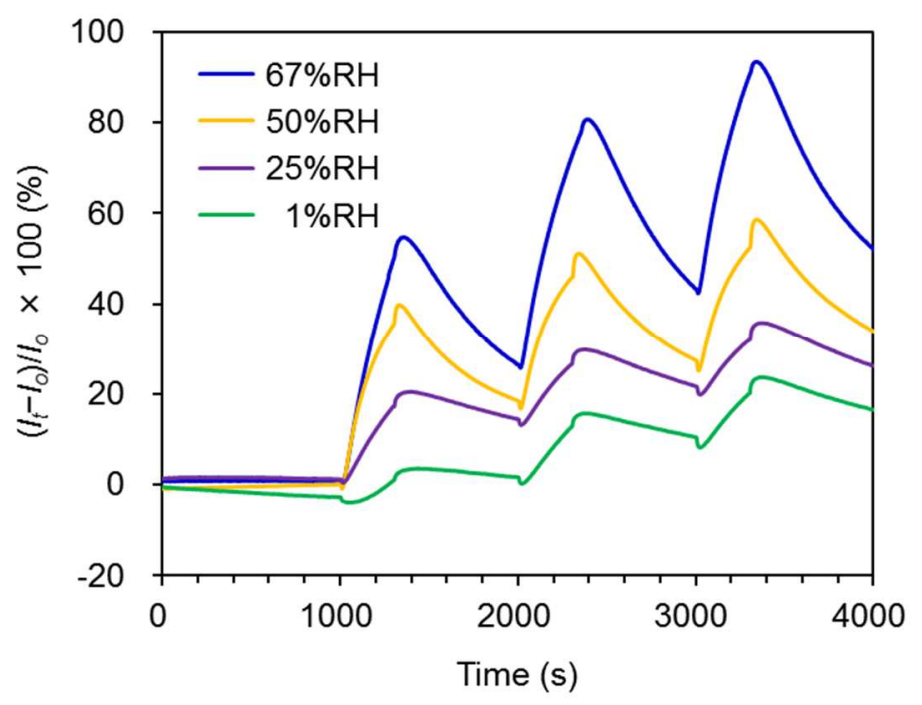

Figure S7. Electric response of sensors for ethylene (10 ppm) in air $(1,25,50$, and $67 \% \mathrm{RH}$, $\left.25 \mathrm{~mL} \mathrm{~min}{ }^{-1}\right)$. Analyte gases were passed through $\mathrm{Pd}_{-} \mathrm{V}_{2} \mathrm{O}_{5}-\mathrm{TiO}_{2}(200 \mathrm{mg})$ kept at $40{ }^{\circ} \mathrm{C}$. Exposure to clean air $(700 \mathrm{sec})$ and catalyst-passed analyte air $(300 \mathrm{sec})$ were repeated for three times. Experimental set-up is based on Figure 2a. 


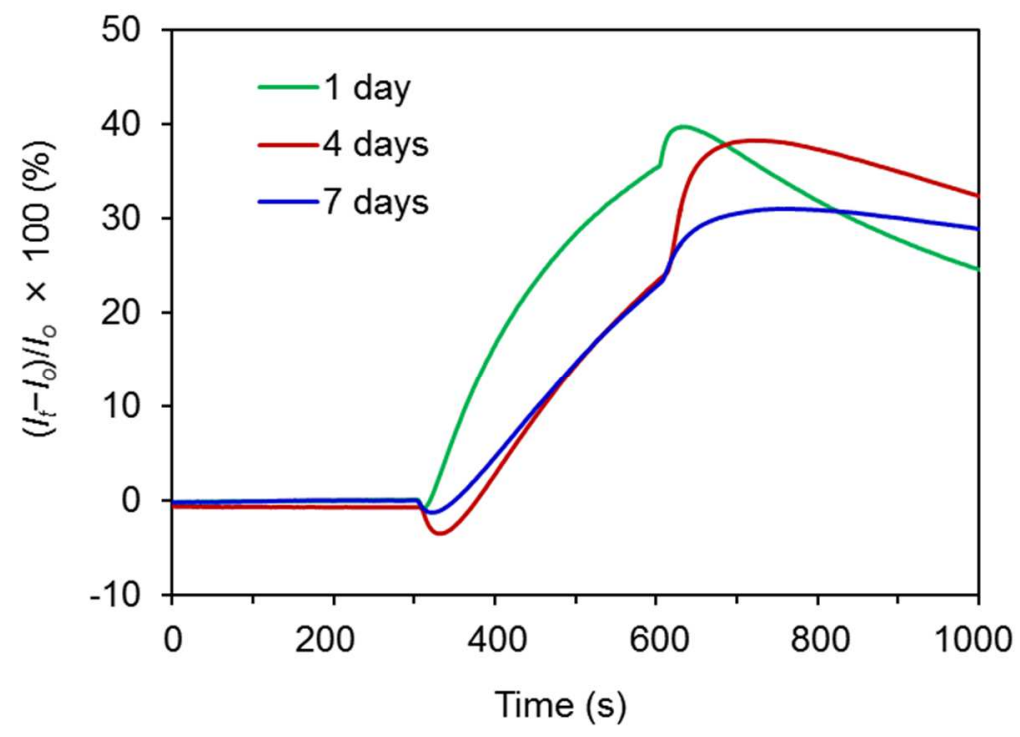

Figure S8. Stability of sensor after 1, 4, 7 days of operation. Electric response of sensors for ethylene (10 ppm) in air $\left(50 \% \mathrm{RH}, 25 \mathrm{~mL} \mathrm{~min}^{-1}\right)$ was tested. Analyte gases were passed through $\mathrm{Pd}-\mathrm{V}_{2} \mathrm{O}_{5}-\mathrm{TiO}_{2}(200 \mathrm{mg}) \mathrm{kept}$ at $40{ }^{\circ} \mathrm{C}$. Sensor was exposed to catalyst-passed analyte air for $300 \mathrm{sec}$. Experimental set-up is based on Figure 2a.

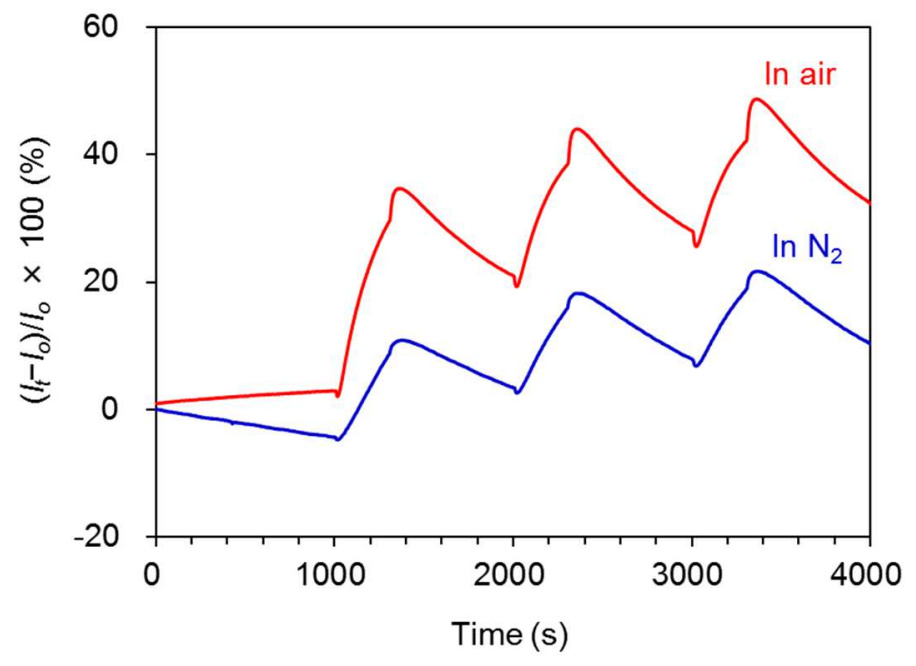

Figure S9. Electric response of sensors for ethylene $(10 \mathrm{ppm})$ in air or $\mathrm{N}_{2}(50 \% \mathrm{RH}, 25 \mathrm{~mL}$ $\left.\mathrm{min}^{-1}\right)$. Analyte gases were passed through $\mathrm{Pd}_{-} \mathrm{V}_{2} \mathrm{O}_{5}-\mathrm{TiO}_{2}(200 \mathrm{mg})$ kept at $40{ }^{\circ} \mathrm{C}$. Exposure to clean gas $(700 \mathrm{sec})$ and catalyst-passed analyte gas $(300 \mathrm{sec})$ were repeated for three times. Experimental set-up is based on Figure 2a. 

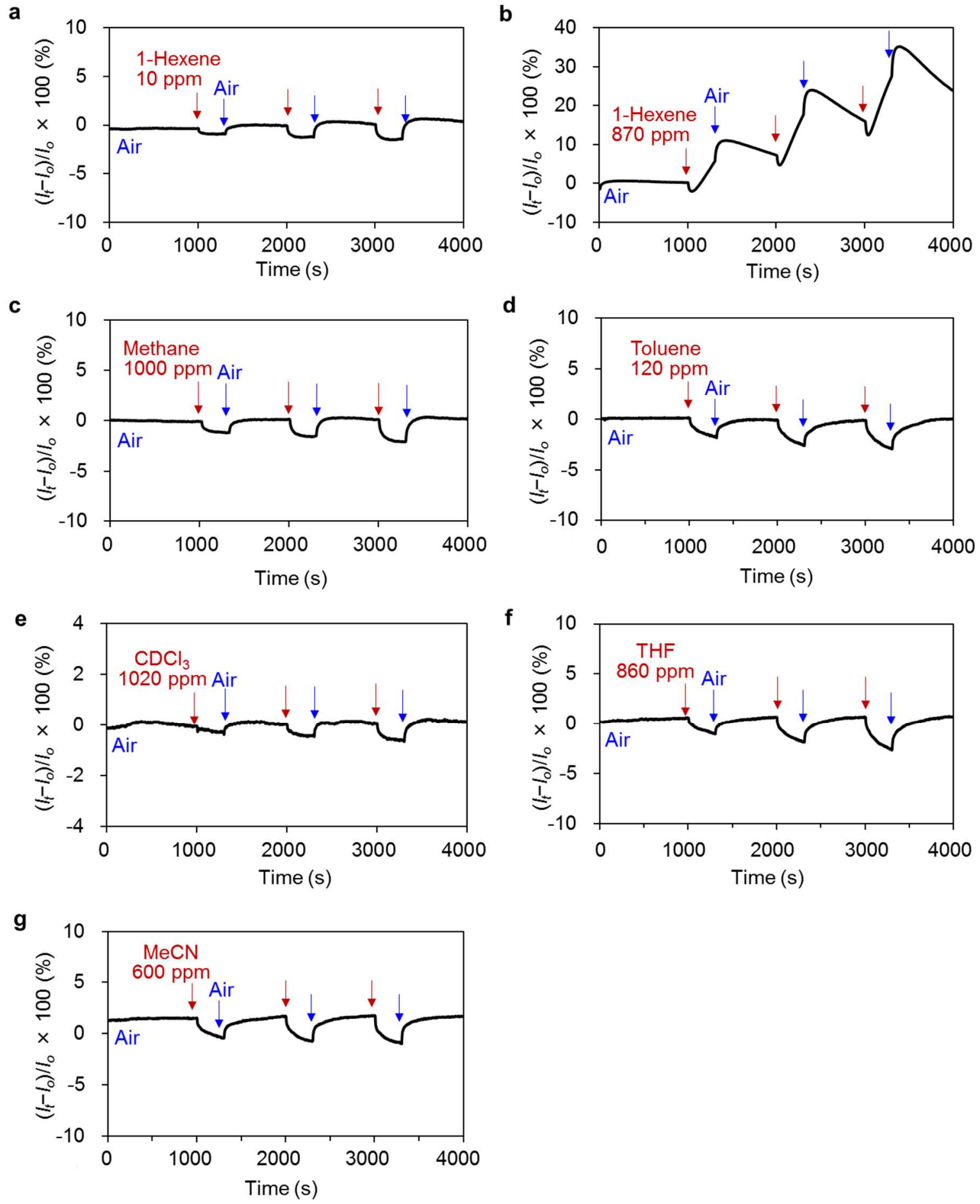

Figure S10. Electric response of sensors for various gases in air $\left(50 \% \mathrm{RH}, 25 \mathrm{~mL} \mathrm{~min}^{-1}\right)$. (a, b) 1-Hexene, (c) methane, (d) toluene, (e) $\mathrm{CDCl}_{3}$, (f) THF, and (g) MeCN. Analyte gases were passed through $\mathrm{Pd}-\mathrm{V}_{2} \mathrm{O}_{5}-\mathrm{TiO}_{2}(200 \mathrm{mg})$ kept at $40{ }^{\circ} \mathrm{C}$. Exposure to clean gas $(700 \mathrm{sec})$ and catalyst-passed analyte gas $(300 \mathrm{sec})$ were repeated for three times. Experimental set-up is based on Figure 2a. 

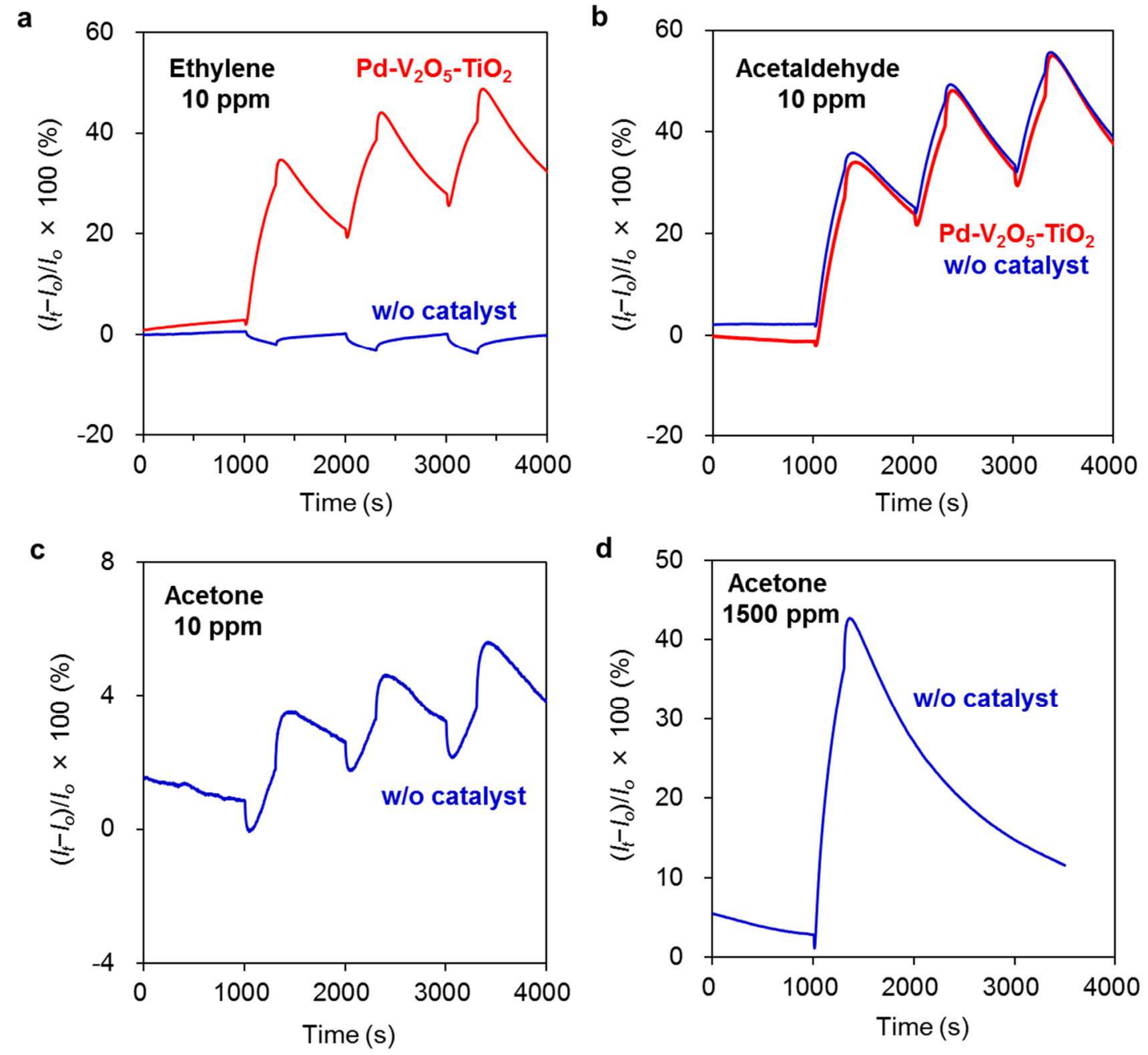

Figure S11. Electric response of sensors for (a) ethylene, (b) acetaldehyde, and (c, d) acetone in air (50\% RH, $25 \mathrm{~mL} \mathrm{~min}{ }^{-1}$ ). Analyte gases were passed through $\mathrm{Pd}_{-} \mathrm{V}_{2} \mathrm{O}_{5}-\mathrm{TiO}_{2}(200 \mathrm{mg}) \mathrm{kept}$ at $40{ }^{\circ} \mathrm{C}$. Exposure to clean gas $(700 \mathrm{sec})$ and catalyst-passed analyte gas $(300 \mathrm{sec})$ were tested. Experimental set-up is based on Figure 2a. 

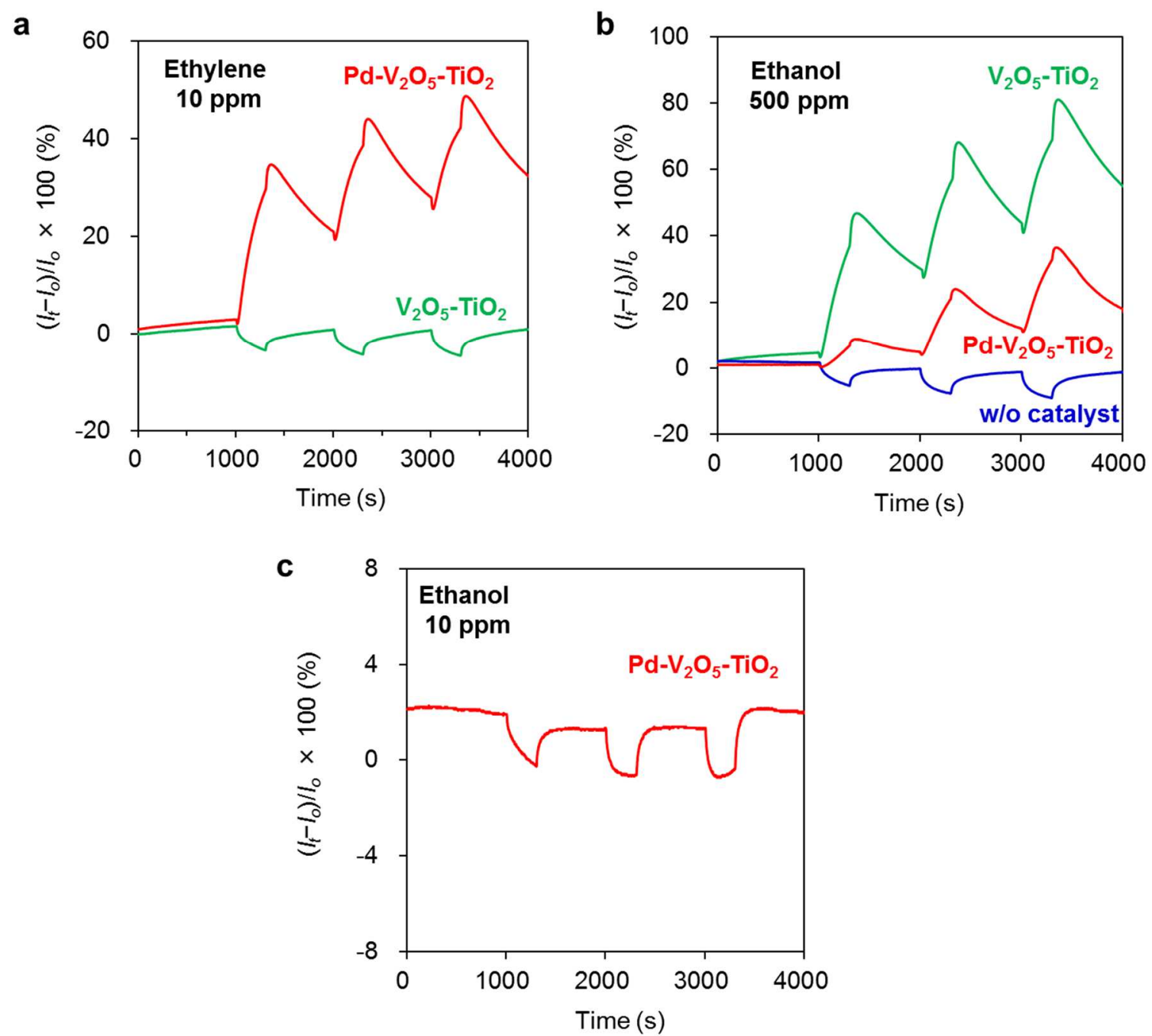

Figure S12. Electric response of sensors for (a) ethylene and (b, c) ethanol in air (50\% RH, 25

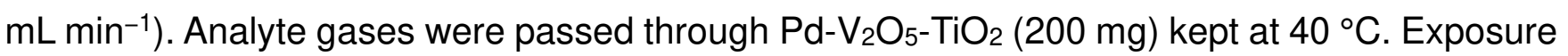
to clean gas $(700 \mathrm{sec})$ and catalyst-passed analyte gas $(300 \mathrm{sec})$ were repeated. Experimental set-up is based on Figure 2a. 


\section{Determination of limit of detection (LoD)}

Figure $\mathrm{S} 13$ is the magnified image of Figure $2 \mathrm{c}$ in the main manuscript. Limit of detection (LoD) of sensing response is described by equation (S1). ${ }^{S 4}$

$$
\text { LoD }=\text { meanblank }+1.645 \times \text { Oblank }+1.645 \times \text { Glowest conc. }
$$

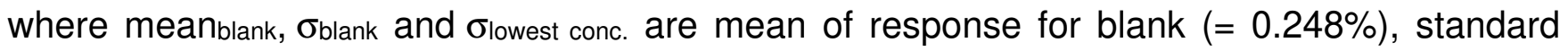
deviation of response for blank $(=0.0763 \%)$ and $1 \mathrm{ppm}$ ethylene $(=1.22 \%)$, respectively. LoD of response is estimated to be $2.38 \%$, which corresponds to $0.197 \mathrm{ppm}$ of ethylene based on initial response $y=10.8 x+0.248$. Note that the initial approximation (by red line in Figure S13) yields the value of slope $=10.8$ which is the lowest possible estimate. This indicates that our calculated $\mathrm{LoD}=0.197 \mathrm{ppm}$ is very conservative and realistic value.

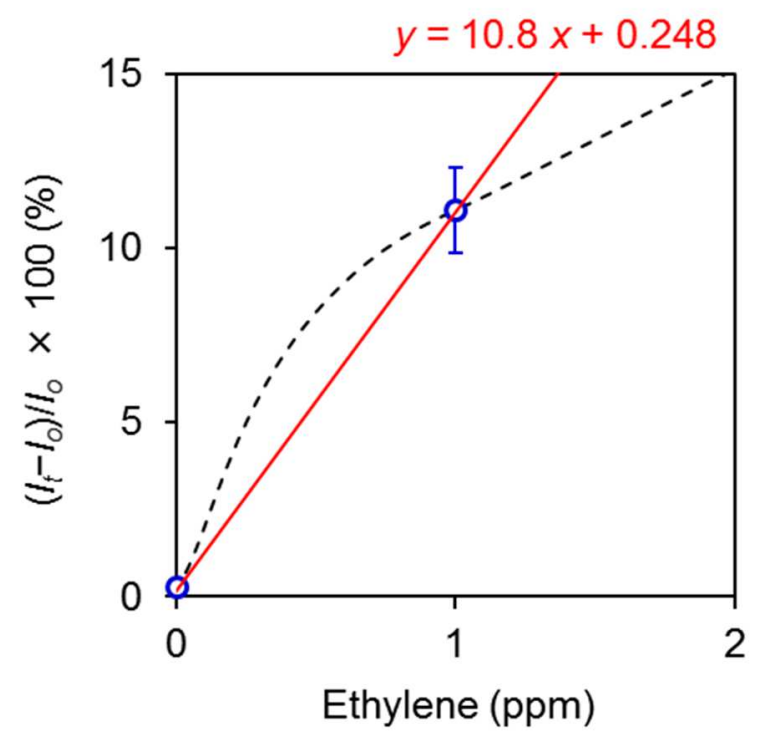

Figure S13. Sensing response for 0 and $1 \mathrm{ppm}$ ethylene gases (magnified image of Figure 2c in the main manuscript). 


\section{References}

S1 Ishihara, S.; Labuta, J.; Nakanishi, T.; Tanaka, T.; Kataura, H. Amperometric Detection of Sub-ppm Formaldehyde using SWCNTs and Hydroxylamines: A Referenced Chemiresistive System. ACS Sens. 2017, 2, 1405-1409.

S2 Yomogida, Y.; Tanaka, T.; Zhang, M.; Yudasaka, M.; Wei, X.; Kataura, H. Industrial-scale Separation of High-purity Single-chirality Single-wall Carbon Nanotubes for Biological Imaging. Nat. Commun. 2016, 7, 12056.

S3 Ishihara, S.; Azzarelli, J. M.; Krikorian, M.; Swager, T. M. Ultratrace Detection of Toxic Chemicals: Triggered Disassembly of Supramolecular Nanotube Wrappers. J. Am. Chem. Soc. 2016, 138, 8221-8227.

S4 Armbruster, D. A.; Pry, T. Limit of Blank, Limit of Detection and Limit of Quantitation. Clin. Biochem. Rev. 2008, 29, S49-S52. 